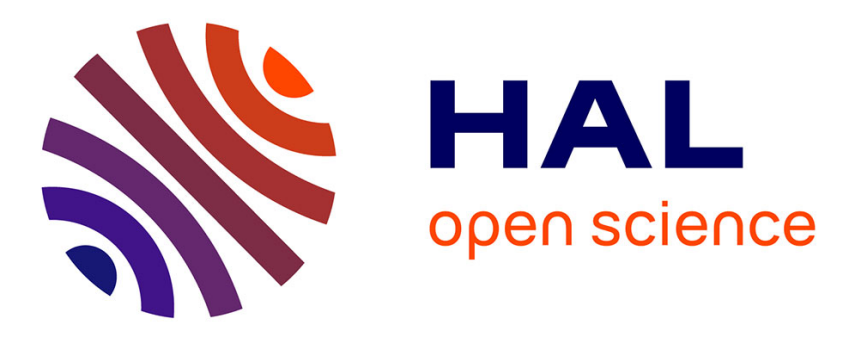

\title{
Taylor dispersion analysis coupled to ICP-MS for ultrasmall nano-particle size measurement: from drug product to biological media studies
}

Lucie Labied, Paul Rocchi, Tristan Doussineau, Jérôme Randon, Olivier Tillement, François Lux, Agnès Hagège

\section{To cite this version:}

Lucie Labied, Paul Rocchi, Tristan Doussineau, Jérôme Randon, Olivier Tillement, et al.. Taylor dispersion analysis coupled to ICP-MS for ultrasmall nano-particle size measurement: from drug product to biological media studies. Analytical Chemistry, 2021, 93 (3), pp.1254-1259. 10.1021/acs.analchem.0c03988 . hal-03093902

\section{HAL Id: hal-03093902 \\ https://hal.science/hal-03093902}

Submitted on 4 Jan 2021

HAL is a multi-disciplinary open access archive for the deposit and dissemination of scientific research documents, whether they are published or not. The documents may come from teaching and research institutions in France or abroad, or from public or private research centers.
L'archive ouverte pluridisciplinaire HAL, est destinée au dépôt et à la diffusion de documents scientifiques de niveau recherche, publiés ou non, émanant des établissements d'enseignement et de recherche français ou étrangers, des laboratoires publics ou privés. 


\title{
Taylor dispersion analysis coupled to ICP-MS for ultrasmall nano- particle size measurement: from drug product to biological media studies
}

\author{
Lucie Labied ${ }^{\dagger, \ddagger}$, Paul Rocchi ${ }^{\ddagger}, \|$, Tristan Doussineau", Jérôme Randon ${ }^{\dagger}$, Olivier Tillement ${ }^{\ddagger}$, François \\ Lux ${ }^{\ddagger}$, , Agnès Hagège ${ }^{*}, \dagger$ \\ ${ }^{\dagger}$ Institut des Sciences Analytiques, UMR 5280, Université de Lyon, CNRS, Université Claude Bernard Lyon 1, 69100 Vil- \\ leurbanne, France, e-mail : agnes.hagege@isa-lyon.fr \\ ¥Institut Lumière Matière, Université Claude Bernard Lyon 1, CNRS UMR 5306, 69622 Villeurbanne, France \\ 'NH TherAguix S.A.S., 29 Chemin du Vieux Chêne, 38240 Meylan, France \\ §Institut Universitaire de France (IUF), Paris, France
}

\begin{abstract}
During last decade, special focus has been laid on ultrasmall nanoparticles for nanomedicine and eventual clinical translation. To achieve such translation, a lot of challenges have to be solved. Among them, size determination is a particularly tricky one. In this aim, we have developed a simple hyphenation between Taylor dispersion analysis and ICP-MS. This method was proven to allow the determination of the hydrodynamic radius of metal-containing nanoparticles, even for sizes under $5 \mathrm{~nm}$, with a relative standard deviation below $10 \%$ (with a $95 \%$ confidence interval) and at low concentrations. Moreover, its specificity provides the opportunity to perform measurements in complex biological media. This was applied to the characterization of an ultrasmall gadolinium-containing nanoparticle, used as theranostic agent in cancer diseases. Hydrodynamic radii measured in urine, cerebrospinal fluid and undiluted serum demonstrated the absence of interaction between the particle and biological compounds such as proteins.
\end{abstract}

Metallic and hybrid ultrasmall nanoparticles (USNPs) (diameters $<10 \mathrm{~nm}$ ) have attracted a growing interest in recent years, particularly in medical fields. Due to their size, they are able to be quickly eliminated by the kidneys, ${ }^{1}$ thus decreasing their potential toxicity. Numerous applications of these USNPs have been proposed not only for diagnostics but also for therapy, mainly for cancer treatment. ${ }^{2-6}$ However, only a few of these nanodrug candidates reach the clinical trials. Besides $\mathrm{Fe}$ raheme ${ }^{\circledR}$, an iron oxide USNP used for chronic kidney disease, only Nanotherm ${ }^{\circledR}$ and Cornell dots ${ }^{4}$ have been approved by FDA (Food and Drug Administration) and AGuIX ${ }^{5}$ by ANSM (Agence Nationale de Sécurité du Médicament, French equivalent of FDA), for first-in-human clinical trials in cancer therapy.

As pointed out by K. Zarschler et al., ${ }^{6}$ one of the main issues limiting the passage in the clinic of these promising nano-objects is the lack of methods allowing their physicochemical characterization, particularly in biological media, to answer regulatory agencies requirements.

An important feature that governs the fate of nanoparticles in the organism is their size. Interactions with biological objects ${ }^{7-}$ ${ }^{9}$, clearance pathways ${ }^{1,10}$ or tumor penetration ${ }^{11}$ depend on the hydrodynamic size taken by a nano-object in the organism, which can drastically differ from the size measured in a simple aqueous buffer. Orthogonal analytical approaches for nanoparticles sizing becomes a pre-requisite. ${ }^{12}$

The precise measurement of USNPs' size is in itself a challenge, and is even more problematic when these particles are in a complex biological medium containing other similarly sized or much bigger biomolecules such as proteins. A fast and reliable sub-nanometric to several tens of nanometers sizing method is needed in order to assess metallic and hybrid USNPs' size variations in biological media, due to particle degradation, dissolution, but also aggregation or interactions with proteins, in a fast and reliable way.

The gold standard method for size characterization in routine is DLS (Dynamic Light Scattering), thanks to its speed and ease of use. However, its non-specificity and the important bias towards larger objects prevent an accurate size determination for USNPs in complex media.

In order to gain specificity, many methods using specific detection, mostly ICP-MS (Inductively Coupled Plasma/Mass Spectrometry), have been developed.

Recently, single-particle ICP-MS (sp-ICP-MS) has been introduced for size measurement of metal-based nanoparticles. However, this method is not adapted to the challenges raised by hybrid USNPs. Since nanoparticle size is determined from signal intensity, the size threshold for monoatomic nanoparticles depends heavily on the composition: silver nanoparticles have a size threshold of 10 to $20 \mathrm{~nm}$, while silica nanoparticles must be at least $200 \mathrm{~nm}$ in diameter to be detected. ${ }^{13}$ Moreover, the method may require a calibration with particle standards, ${ }^{14}$ and the sizing of hybrid nanoparticles is still undergoing development. ${ }^{15,16}$

Hyphenated separative methods with ICP-MS have been proposed for nanoparticles size measurement. Several studies have reported the use of asymmetric flow field flow fractionationICP-MS, ${ }^{17,18}$ size exclusion chromatography-ICP-MS ${ }^{19}$ and capillary electrophoresis (CE)-ICP-MS ${ }^{20}$ for nanoparticles sizing. 
However, the resolving power of these techniques often limits the size range and most of these studies have been dedicated to $10 \mathrm{~nm}-100 \mathrm{~nm}$ particles.

Taylor Dispersion Analysis (TDA) is an absolute hydrodynamic size measurement based on the determination of the molecular diffusion coefficient from the dispersion of a solute plug in a laminar flow. ${ }^{21}$ It has so far mostly relied on UV detection and the hyphenation of TDA to more specific detection methods, namely backscattering interferometry for polysaccharides sizing, ${ }^{22}$ or mass spectrometry to provide additional information about protein conformation, ${ }^{23}$ is still ongoing.

The development of TDA hyphenated to ICP-MS, presented here for the first time, could be extremely valuable for the characterization of metal-based and hybrid nanoparticles of a wide range of sizes and compositions, in both simple and complex matrices, and most importantly for USNPs in biological media.

As a proof of concept, TDA-ICP-MS was used for measuring the size of $\mathrm{AGuIX}{ }^{\circledR}$, a gadolinium-containing theranostic nanoparticle (see SI ,Figure S1), which has shown great promise in clinical trials for cancer therapy, in different media.

\section{EXPERIMENTAL PART}

Materials. The capillaries were untreated fused-silica capillaries (70 cm x $75 \mathrm{~mm}$ i.d., $375 \mathrm{~mm}$ o.d.) from Photon Lines.

AGuIX ${ }^{\circledR}$ product was provided by NH TherAguix as a powder for solution, containing gadolinium-chelated polysiloxane-nanoparticles. Solutions were prepared extemporaneously before analysis.

Tris, $\mathrm{NaCl}$ and $\mathrm{HCl}$ obtained from Sigma were dissolved in ultra-pure water for the preparation of the mobilization solutions.

1,4,7,10-tetraazacyclododecane-1,4,7,10-tetraacetic acid mono N-hydroxysuccinimide ester (DOTA-NHS, Chematech), Gd $10000 \mathrm{mg} / \mathrm{L}$ in $1 \% \mathrm{HNO}_{3}$ (ICP-MS standard, SCP Science) and bovine serum albumin (BSA, Sigma) were used for Gd-labelled BSA synthesis (see SI Figure S2).

Human serum albumin (HSA), serum and synthetic urine were also purchased from Sigma. Porcine cerebrospinal fluid was kindly provided by MexBrain.

Instrumentation. TDA experiments were performed on a 7100 capillary electrophoresis instrument (Agilent Technologies). Prior to the first use, the capillary was coated with hydroxypropylcellulose (HPC) according to the procedure described by Shen et al. $^{24}$ and then flushed with the running buffer for $5 \mathrm{~min}$ under 1 bar. Between runs, the capillary was washed with the electrolyte buffer for 2 min under 1 bar.

For Gd detection, a Nexion 300X ICP--MS (Perkin Elmer) equipped with a PFA microflow nebulizer was used for the specific detection of gadolinium. Signal at m/z 158 was monitored using an integration time of $500 \mathrm{~ms}$. Operating conditions were tuned in order to maximize the signal: nebulizer gas flow rate: $0.95 \mathrm{~L} / \mathrm{min}$, plasma gas flow rate: $18 \mathrm{~L} / \mathrm{min}$, auxiliary gas flow rate: $1.2 \mathrm{~L} / \mathrm{min}$, radiofrequency power $1600 \mathrm{~W}$ for the plasma, dwell time: $500 \mathrm{~ms}$.

The hyphenation between CE and ICP-MS was achieved via a homemade sheath-flow interface (Figure 1 and SI, Figure S3). The capillary goes first through a T-connector toward the tip of the nebulizer. The sheath liquid $\left(\mathrm{HNO}_{3} 1 \mathrm{mM}\right)$ was introduced by self-aspiration to the third inlet of the interface. Using such a sheath liquid allows to overcome potential matrix effects of the different biological media.

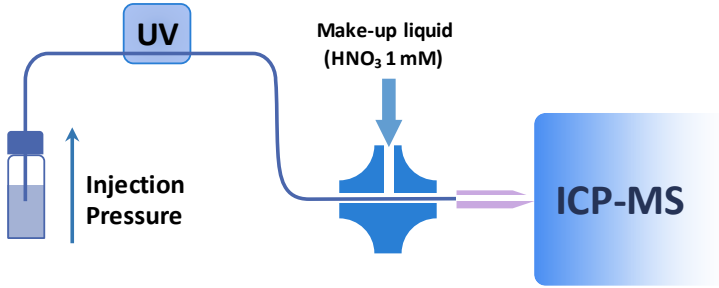

Figure 1. Experimental set-up for TDA-ICP-MS hyphenation.

CE system control and UV data acquisition were carried out using the Chemstation software (Agilent) and ICP-MS controlled and data acquired using the Syngistix software (Perkin Elmer).

TDA experiments. AGuIX ${ }^{\circledR}$ was diluted at $0.5 \mathrm{~g} / \mathrm{L}$ in the different media and immediately analyzed. Samples were hydrodynamically injected ( 20 mbar for $3 \mathrm{~s}$ ). The mobilization pressure was kept constant at 50 mbar. Solutes were monitored by UV absorbance at $200 \mathrm{~nm}$, at $21.6 \mathrm{~cm}$ from the capillary inlet and by ICP-MS, at $\mathrm{m} / \mathrm{z}=158$, at the end of the same capillary. For synthetic urine, the capillary was rinsed at 1 bar for 5 min with $\mathrm{HNO}_{3} 1 \mathrm{mM}$ and $5 \mathrm{~min}$ with synthetic urine between runs.

DLS controls. AGuIX ${ }^{\circledR}$ was diluted at $10 \mathrm{~g} / \mathrm{L}$ in either pure water or diluted serum, filtered with $0.2 \mu \mathrm{m}$ filters and immediately analyzed. Measurements were performed using a Zetasizer Nano-S (633 nm He-Ne laser) from Malvern In-struments (USA). Measurements were averaged over 20 individual measurements, performed 5 times at $25^{\circ} \mathrm{C}$. The validity of the data was determined by examination of both the autocorrelation curves and the quality report.

\section{RESULTS AND DISCUSSION}

TDA allows for the determination of the hydrodynamic radius of objects in the sub-nanometer to several hundreds of nanometers range, ${ }^{25-27}$ through the determination of the molecular diffusion coefficient. A solute is injected in a capillary and a mobilization pressure is applied. The detected peak can be fitted by a Gaussian distribution, according to the following equation:

$S(t)=y_{0}+\frac{A}{\sigma \sqrt{2 \pi}} \exp \left(-\frac{1}{2} \frac{\left(t-t_{0}\right)^{2}}{\sigma^{2}}\right)$

Where $t$ is the experimental time, $t_{0}$ and $\sigma$ are the mean and temporal variance of the fitted Gaussian distribution respectively, $y_{0}$ the baseline intensity and $A$, a constant depending on the detection sensitivity and the concentration of the sample.

Under experimental conditions described by Chamieh et al., ${ }^{26}$ the molecular diffusion coefficient $\mathrm{D}$ is given by

$D=\frac{R_{C}^{2} t_{0}}{24 \sigma^{2}}=\frac{k_{B} T}{6 \pi \eta R_{h}}$

where $R_{c}$ is the capillary radius, $k_{B}$ is the Boltzmann constant, $T$ is the temperature, $\eta$ is the viscosity, and $R_{h}$ is the hydrodynamic radius of the solute.

Since the hydrodynamic radius of a solute is based on the Gaussian fit of the peak obtained in TDA, the accuracy of the determination relies on (i) minimization of other contributions to the peak variance (ii) detection sensitivity which directly affects the quality of the fit.

Validation of TDA-ICP-MS hyphenation. Since the determination of $R_{h}$ is directly related to the variance of the peak, it is of utmost importance to ensure that the hyphenation does not introduce any significant external dispersion. For that purpose, a Gd-labelled BSA was used. This sample was assumed to be 
stable all along the capillary. In such experimental design, Gdlabelled BSA can be detected by both UV (before the T-junction) and ICP-MS (after the T-junction) detectors in a single experiment. Figure 2 shows the results obtained with both UV and ICP-MS detections. Both signals have been normalized by their respective maximums. Since the detection occurs at two different mobilization lengths, the data is displayed with a reduced time to allow for direct comparison of the temporal variance (see SI).

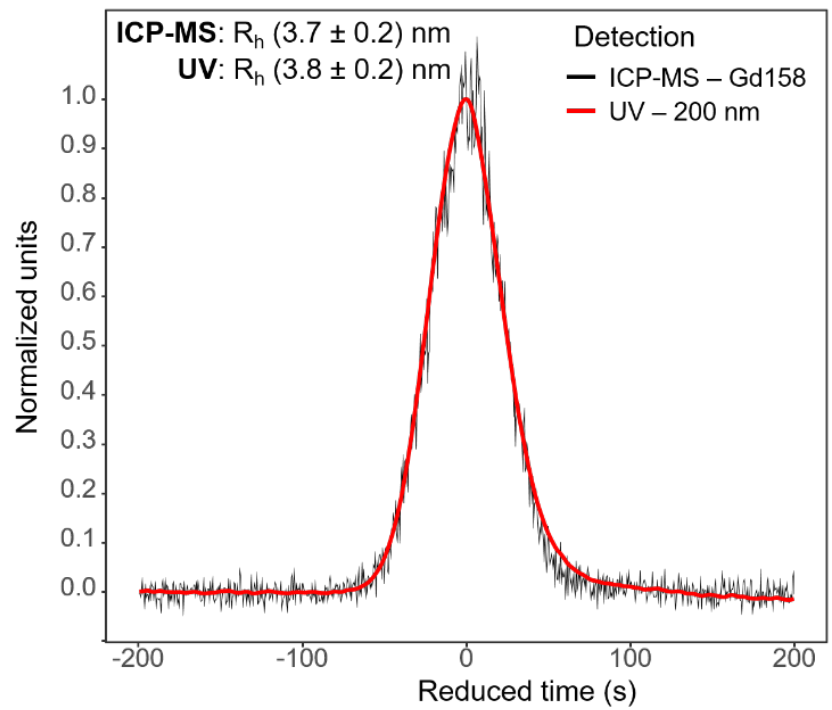

Figure 2. Taylorgrams of Gd-labelled BSA, with both UV and ICPMS detection. Experimental conditions: injection 20 mbar $3 \mathrm{~s}$; HPC capillary $75 \mu \mathrm{m}$ i.d. x $70 \mathrm{~cm}$ length; buffer Tris $10 \mathrm{mM} \mathrm{NaCl} 150$ $\mathrm{mM} \mathrm{pH} \mathrm{7.4;} \mathrm{mobilization} \mathrm{pressure} 50$ mbar; ICP-MS detection $\mathrm{m} / \mathrm{z}$ $=158$; UV detection window at $21.6 \mathrm{~cm}$, wavelength $200 \mathrm{~nm}$. Radii are given with a $95 \%$ confidence interval.

Figure 2 shows a nearly perfect superposition of the two taylorgrams, with very similar calculated radii of $(3.8 \pm 0.2)$ and (3.7 $\pm 0.2) \mathrm{nm}$, given with a $95 \%$ confidence interval, with UV and ICP-MS detection respectively, demonstrating that the broadening generated by the interface can be neglected.

Size determination of an ultrasmall nanoparticle by TDAICP-MS. This method has been applied to the sizing of the AGuIX ${ }^{\circledR}$ USNP, at different $\mathrm{pH}$. According to Chamieh et al.,$^{26}$ the choice of a $75 \mu \mathrm{m}$ i.d. capillary allows the perfect sizing range for a USNP, as well as the detection of possible degradation or aggregation phenomena $(0.2-50 \mathrm{~nm}$ hydrodynamic radii).

Measured hydrodynamic radii for AGuIX ${ }^{\circledR}$ USNP are shown in table 1. The method shows great precision in aqueous buffers, with a relative standard deviation on hydrodynamic radii not exceeding 10\%. For comparison, measurements obtained for EDTA-Gd and DOTAGA-Gd are given as SI (Table S1) and demonstrate the potential of the method for small molecules.

Table 1. Mean hydrodynamic radius of AGuIX® USNP measured by TDA-ICP-MS, using Tris NaCl buffer at various pH

$\begin{array}{ccc}\mathrm{pH} & \text { Mean } \mathrm{R}_{\mathrm{h}}(\mathrm{nm})^{\mathrm{a}} & \text { number of analyses } \\ 2.3 & 2.3 \pm 0.1 & 3 \\ 3.2 & 2.3 \pm 0.1 & 4 \\ 5.5 & 2.3 \pm 0.1 & 4\end{array}$

$\begin{array}{lll}6.7 & 2.2 \pm 0.1 & 3 \\ 7.4 & 2.3 \pm 0.2 & 7 \\ 8.2 & 2.3 \pm 0.1 & 3\end{array}$

${ }^{a}$ Mean hydrodynamic radius extrapolated from Gaussian fittings of TDA-ICP-MS experiments, given with a 95\% confidence interval. Experimental conditions: AGuIX ${ }^{\circledR}$ diluted at $0.5 \mathrm{~g} / \mathrm{L}$ in buffer. injection 20 mbar $3 \mathrm{~s}$; HPC capillary $75 \mu \mathrm{m}$ i.d. x $70 \mathrm{~cm}$ length; buffer Tris $10 \mathrm{mM} \mathrm{NaCl} 150 \mathrm{mM} \mathrm{pH}$ 2.3-8.2; mobilization pressure $50 \mathrm{mbar}$; ICP-MS detection $\mathrm{m} / \mathrm{z}=158$.

Hydrodynamic radii obtained with TDA (on average $2.3 \pm 0.2$ $\mathrm{nm}$ over 7 repetitions, in Tris $\mathrm{NaCl}$ buffer at $\mathrm{pH} 7.4$ ) are in agreement with those obtained by DLS $(2.8 \pm 0.4 \mathrm{~nm})$ (figure 3 ). The goodness of the fit strongly supports the assumption of the main monodisperse character of the USNP, although a slight polydispersity can be deduced from the taylorgram (figure 3a), characterized by the deviation between the Gaussian fit and the acquired signal, most notably at the bottom and at the top of the peak. ${ }^{28}$ This observation is also in agreement with DLS data. To date, although some research is in progress, ${ }^{29}$ polydispersity is not easily quantifiable in TDA, due to the lack of reference methods.

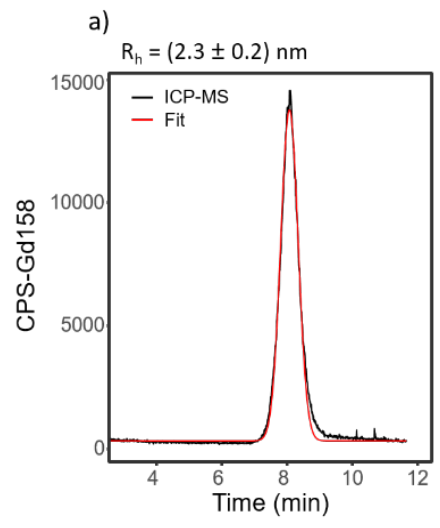

b)

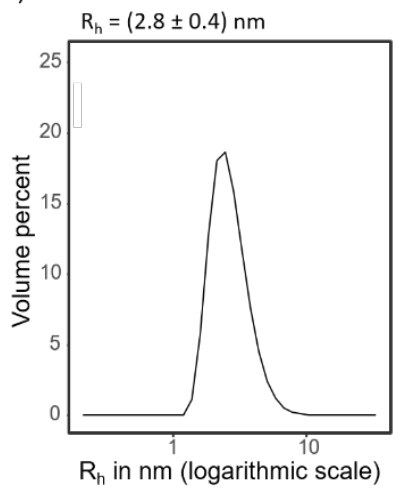

Figure 3. a) Representative taylorgram of $\mathrm{AGuIX}{ }^{\circledR}$ (black line), with the corresponding Gaussian fitting (red line). Experimental conditions: $A G u I X{ }^{\circledR}$ diluted at $0.5 \mathrm{~g} / \mathrm{L}$ in buffer. injection $20 \mathrm{mbar}$ $3 \mathrm{~s}$; HPC capillary $75 \mu \mathrm{m}$ i.d. x $70 \mathrm{~cm}$ length; buffer Tris $10 \mathrm{mM}$ $\mathrm{NaCl} 150 \mathrm{mM} \mathrm{pH}$ 7.4; mobilization pressure 50 mbar; ICP-MS detection $\mathrm{m} / \mathrm{z}=158 . \mathrm{b})$ Representative DLS of AGuIX ${ }^{\circledR}$. Experimental conditions: $\mathrm{AGuIX}{ }^{\circledR}$ diluted at $10 \mathrm{~g} / \mathrm{L}$ in water.

Quantification of the Gd content in the USNP was performed using EDTA standards. A concentration of $(73 \pm 4) \mathrm{mM}$, was found in a $100 \mathrm{~g} / \mathrm{L} \mathrm{AGuIX}{ }^{\circledR}$ solution and was in agreement with the concentration found by ICP-MS after mineralization (71 $\mathrm{mM})$.

The detection and quantification limits, depending on the peak variance, were estimated to be respectively $0.6 \mu \mathrm{M}$ and $2 \mu \mathrm{M}$ Gd (SI, Figure S4). However, due to AGuIX ${ }^{\circledR}$ dissolution upon dilution, these limits cannot be reached. (SI, Figure S5)

From these results, advantages afforded by TDA-ICP-MS over DLS can be pointed out. DLS for a low-absorbing hybrid USNP such as $\mathrm{AGuIX}{ }^{\circledR}$ requires a high concentration for a reliable size estimation. In routine, DLS AGuIX ${ }^{\circledR}$ sizing must be done with a $10 \mathrm{~g} / \mathrm{L}$ sample solution. However, thanks to the specific and sensitive detection of ICP-MS, the lowest concentration where AGuIX ${ }^{\circledR}$ sizing by TDA was still possible was estimated 
at $0.05 \mathrm{~g} / \mathrm{L}, 200$ times less concentrated than in DLS (SI, Figure S5).

Furthermore, the volume required for both buffer and sample solution is likewise drastically lower for TDA. A full analysis, including capillary conditioning, can be done with $50 \mu \mathrm{L}$ of buffer solution and $2 \mu \mathrm{L}$ of sample solution, compared to $1 \mathrm{~mL}$ for DLS. Considering an injected volume of $8 \mathrm{~nL}$, the hydrodynamic radius measurement of $\mathrm{AGuIX}{ }^{\circledR}$ can be routinely performed on $10^{12}$ nanoparticles ( $0.5 \mathrm{~g} / \mathrm{L}$ solution).

Moreover, the multielemental character of the ICP-MS detection can be used for multiplex assays, allowing the simultaneous determination of sizes of different nanoparticles (see SI, Figure S6)

TDA-ICP-MS for sizing USNPs in biological media. Such experimental requirements for TDA-ICP-MS makes this method a prime candidate for application in biological media. Since after injection to the patient, AGuIX ${ }^{\circledR}$ can be considered to be diluted to approximately $1 \mathrm{~g} / \mathrm{L}$ in the blood, the minimum required concentration of $0.05 \mathrm{~g} / \mathrm{L}$ means that in vivo conditions can be reproduced in vitro. The low volume requirements, inherent to the use of a capillary, is likewise important for biological fluids. Thanks to the hyphenation with a Gd-specific detection, complex matrices such as blood serum can be analyzed without any interferences.

In order to estimate the size of $A G u I X ®$ in a given biological fluid by TDA, the capillary was conditioned with each tested medium, and the USNP was diluted in the same medium. The acquired taylorgrams are shown in figure $4 \mathrm{a}$ for Tris $10 \mathrm{mM}$ $\mathrm{NaCl} 150 \mathrm{mM}$, cerebrospinal fluid, synthetic urine, HSA 5g/L, and undiluted serum.

a)

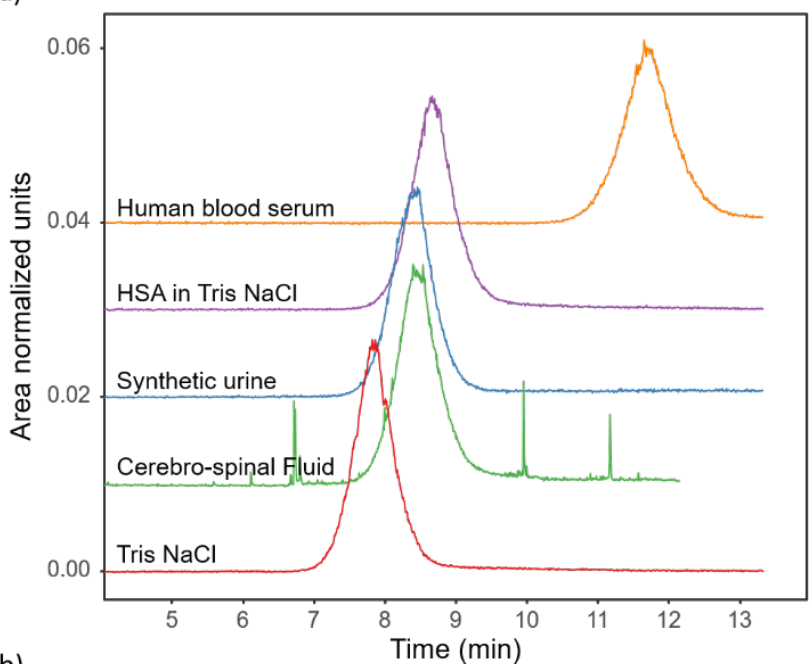

b)

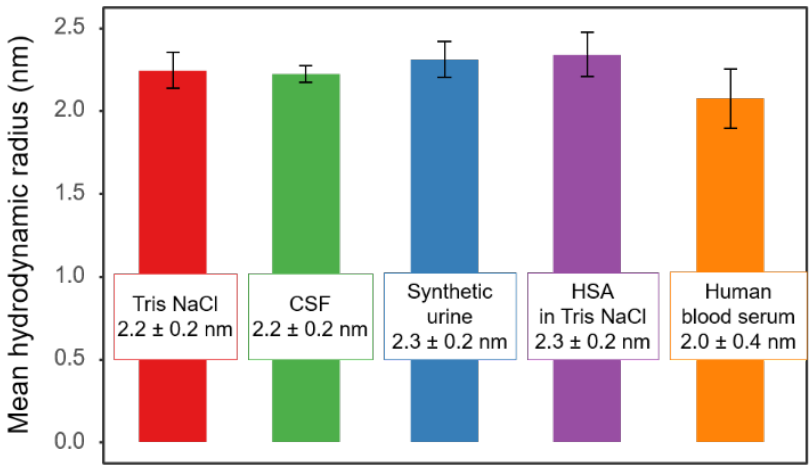

Figure 4. a) Taylorgrams of $A G u I X ®$ in various media. Experimental conditions: $\mathrm{AGuIX}{ }^{\circledR}$ diluted at $0.5 \mathrm{~g} / \mathrm{L}$ in biological medium; injection 20 mbar $3 \mathrm{~s}$; HPC capillary $75 \mu \mathrm{m}$ i.d. x $70 \mathrm{~cm}$ total length; buffer: biological medium; mobilization pressure $50 \mathrm{mbar}$; ICP-MS detection $\mathrm{m} / \mathrm{z}=158$. b) Mean hydrodynamic radii in each tested medium, given with a $95 \%$ confidence interval.

All signals represent Gaussian curves, allowing size determination. Hydrodynamic radii were calculated from at least 3 experiments. The observed variations in average peak residence times are due to the different viscosities of the studied media. The viscosities used for the different biological media were estimated, and are recapitulated in SI, Table S2.

Whatever the medium used, the hydrodynamic radius of $\mathrm{AGuIX}{ }^{\circledR}$ was found constant and around $2.2 \mathrm{~nm}$. Interestingly, the absence of size decrease may indicate that dissolution of the particle, if any, did not occur within a short time period $(<15$ min). These results also support the fact that serum proteins did not interact with the USNP, as already assumed from Synchrotron radiation circular dichroism on mixtures of AGuIX ${ }^{\circledR}$ and HSA. $^{30}$

Most importantly, this analytical procedure was demonstrated to be successfully applied for hydrodynamic radius determination in various complex media, where the classical DLS and TDA-UV lack specificity (see SI, Figures S7 and S8). Hence, the use of a ICP-MS detector coupled to TDA opens new perspectives since it could be easily extended not only to other classes of metallic and hybrid USNPs to determine their behavior in biological media, but also to large biomolecules, such as specifically labelled antibodies.

\section{ASSOCIATED CONTENT}

\section{Supporting Information}

The Supporting Information is available free of charge on the ACS Publications website.

Electronic supplementary information (ESI) available:

Schematic representation of AGuIX ${ }^{\circledR}$ nanoparticles, synthesis of the BSA-DOTA-Gd conjugate and control of the reaction; TDAICP-MS experimental set up; mathematical treatment for superposition of taylorgrams obtained at different lengths; Analytical performances of TDA-ICP-MS ; viscosities of the different media used for the experiments; DLS and TDA-UV experiments performed in a $5 \mathrm{~g} / \mathrm{L}$ HSA solution, diluted and undiluted serum. (PDF)

\section{AUTHOR INFORMATION}

\section{Corresponding Author}

*Phone: +334374235 50. E-mail: agnes.hagege@isa-lyon.fr.

Author Contributions

The manuscript was written through contributions of all authors. All authors have given approval to the final version of the manuscript.

Conflict of interest

FL and OT have to disclose the patent WO2011/135101, that protects the $A G u I X{ }^{\circledR}$ NPs described in this publication. PR, TD, FL and OT are employees from NH TherAguix that is developing the AGuIX nanoparticles and possess shares of this company. 


\section{ACKNOWLEDGMENT}

This work has been supported by a French Government Grant managed by the French National Research Agency (ANR-18-CE170025-02). The authors would like to thank Mexbrain for providing the cerebrospinal fluid.

\section{REFERENCES}

(1) Longmire, M.; Choyke, P. L.; Kobayashi, H. Clearance Properties of Nano-sized Particles and Molecules as Imaging Agents: Considerations and Caveats. Nanomedicine (Lond.) 2008, 3, 703-717.

(2) Yu, Y.; Yang, T.; Sun T. New insights into the synthesis, toxicity and applications of gold nanoparticles in CT imaging and treatment of cancer. Nanomedicine (Lond.) $\mathbf{2 0 2 0} 15,1127-1145$

(3) Fan, M.; Han, Y.; Gao, S.; Yan, H.; Cao, L.; Li, Z.; Liang, X.-J.; Zhang, J. Ultrasmall gold nanoparticles in cancer diagnosis and therapy. Theranostics 2020, 10, 4944-4957.

(4) Chen, F.; Ma, K.; Zhang, L.; Madajewski, B.; Turker, M.Z.; Gallazzi, F.; Cruickshank, K.; Zhang, X.; Jenjitranant, P.; Touijer, K.A.; Quinn, T.P; Zanzonico, P.; Wiesner, U.; Bradbury, M.S. Ultrasmall Renally Clearable Silica Nanoparticles Target ProstateCancer. ACS Appl. Mater. Inter. 2019, 11, 43879-43887.

(5) Verry, C.; Dufort, S.; Lemasson, B.; Grand, S.; Pietras, J.; Troprès, I.; Crémillieux, Y.;. Lux, F.; Mériaux, S.; Larrat, B.; Balosso, J., Le Duc, G.; Barbier, E. L.; Tillement, O. Targeting brain metastases with ultrasmall theranostic nanoparticles, a first-in-human trial from an MRI perspective. Sci. $A d v$., 2020, 6, eaay5279.

(6) Zarschler, K.; Rocks, L.; Licciardello, N.; Boselli, L.; Polo, E.; Pombo Garcia, K.; De Cola, L.; Holger, S.; Dawson, K.A. Ultrasmall inorganic nanoparticles: State-of-the-art and perspectives for biomedical applications. Nanomedicine NBM 2016, 12, 1663-1701.

(7) Lundqvist, M.; Stigler, J.; Elia, G.; Lynch, I.; Cedervall, T.; Dawson, K. A. Nanoparticle size and surface properties determine the protein corona with possible implications for biological impacts. Proc. Natl. Acad. Sci. USA 2008, 105, 14265-14270.

(8) Tenzer, S.; Docter, D.; Rosfa, S.; Wlodarski, A.; Kuharev, J.; Rekik, A.; Knauer, S. K.; Bantz, C.; Nawroth, T.; Bier, C.; Sirirattanapan, J.; Mann, W.; Treuel, L.; Zellner, R.; Maskos, M.; Schild, H.; Stauber, R. H. Nanoparticle Size Is a Critical Physicochemical Determinant of the Human Blood Plasma Corona :A Comprehensive Quantitative Proteomic Analysis. ACS Nano 2011, 5, 7155-7167.

(9) Boselli, L.; Polo, E.; Castagnola, V.; Dawson, K. A. Regimes of Biomolecular Ultrasmall Nanoparticle Interactions. Angew. Chem. Int. Ed. 2017, 56, 4215-4218.

(10) Zhang, Y.-N.; Poon, W.; Tavares, A. J.; Mc Gilvray, I. D.; Chan, W. C. W. Nanoparticle-liver interactions: Cellular uptake and hepatobiliary elimination. J. Control. Release 2016, 240, 332-348.

(11) Popovic, Z.; Liu, W.; Chauhan, V. P.; Lee, J.; Wong, C.; Greytak, A. B.; Insin, N.; Nocera, D. G.; Fukumura, D.; Jain, R. K.; Bawendi, M. G. A Nanoparticle Size Series for In Vivo Fluorescence Imaging. Angew. Chem. Int. Ed., 2010, 49, 8649-8652.

(12) Caputo, F.; Clogston, J.; Calzolai, L.; Rösslein, M.; PrinaMello, A. Measuring particle size distribution of nanoparticle enabled medicinal products, the joint view of EUNCL and NCI-NCL. A step by step approach combining orthogonal measurements with increasing complexity. J. Control. Release 2019, 299, 31-43.

(13) Lee, S.; Bi, X.; Reed, R. B.; Ranville, J. F.; Herckes, P.; Westerhoff, P. Nanoparticle Size Detection Limits by Single Particle ICP-MS for 40 Elements. Environ. Sci. Technol. 2014, 48, 10291-10300.

(14) Pace, H. E.; Rogers, N. J.; Jarolimek, C.; Coleman, V. A.; Higgins, C. P.; Ranville, J. F. Determining Transport Efficiency for the Purpose of Counting and Sizing Nanoparticles via Single Particle Inductively Coupled Plasma Mass Spectrometry. Anal. Chem. 2011, 83, 9361-9369.

(15) Sápi, A.; Kéri, A.; Kálomista, I.; Dobó, D. G.; Ákos Szamosvölgyi, Á. S.; Juhász, K. L.; Ákos Kukovecz, Á. K.; Kónya, Z.; Galbács, G. Determination of the platinum concentration of a Pt/silica nanocomposite decorated with ultra small Pt nanoparticles using single particle inductively coupled plasma mass spectrometry. J. Anal. At. Spectrom. 2017, 32, 996-1003.

(16) Kéri, A.; Kálomista, I.; Ungor, D.; Bélteki, Á.; Csapó, E.; Dékány, I.; Prohaska, T.; Galbács, G. Determination of the structure and composition of Au-Ag bimetallic spherical nanoparticles using single particle ICP-MS measurements performed with normal and high temporal resolution. Talanta 2018, 179, 193-199.

(17) Nwoko, K. C.; Raab A.; Cheyne, L.; Dawson, D.; Krupp, E.; Feldmann J. Matrix-dependent size modifications of iron oxide nanoparticles (Ferumoxytol) spiked into rat blood cells and plasma: Characterisation with TEM, AF4-UV-MALS-ICP-MS/MS and spICP-MS. J. Chromatogr. B 2019, 1124, 356-365

(18) López-Sanz, S.; Rodríguez Fariñas, N.; Rodríguez MartínDoimeadios, R.; Ríos, Á. Analytical strategy based on asymmetric flow field flow fractionation hyphenated to ICP-MS and complementary techniques to study gold nanoparticles transformations in cell culture medium. Anal. Chim. Acta 2019, 1053, 178-185.

(19) Dong, L.; Zhou, X.; Hu, L. Simultaneous size characterization and mass quantification of the in vivo core-biocorona structure and dissolved species of silver nanoparticles. J. Environ. Sci., 2018, 63, 227235.

(20) Liu, L.H.; He, B.; Liu, Q.; Yun, Z. J.; Yan, X. T; Long, Y. M.; Jiang, G. B. Identification and Accurate Size Characterization of Nanoparticles in Complex Media. Angew. Chem. Int. Ed. 2014, 53, 14476-14479.

(21) Taylor, G. I. Dispersion of soluble matter in solvent flowing slowly through a tube. Proc. R. Soc. Lond. A 1953, 219, 186-203.

(22) Saetear, P.; Chamieh, J.; Kammer, M. N.; Manuel, T. J.; Biron, J.-P.; Bornhop, D. J.; Cottet, H. Taylor Dispersion Analysis of Polysaccharides Using Backscattering Interferometry. Anal. Chem. 2017, 89, 6710-6718.

(23) Hong, J.; Wu, H.; Zhang, R.; He, M.; Xu, W. The Coupling of Taylor Dispersion Analysis and Mass Spectrometry to Differentiate Protein Conformations. Anal. Chem. 2020, 92, 5200-5206.

(24) Shen, S.; Berger, J. S.; Anderson, G. A.; Smith, R. D. HighEfficiency Capillary Isoelectric Focusing of Peptides. Anal. Chem., 2000, 72, 2154-2159.

(25) D'Orlyé, F.; Varenne A., Gareil P. Determination of nanoparticle diffusion coefficients by Taylor dispersion analysis using a capillary electrophoresis instrument. J. Chromatogr. A, 2008, 1204, 226232.

(26) Chamieh, J.; Leclercq, L.; Martin, M.; Slaoui, S.; Jensen, H.; Østergaard, J.; Cottet, H. Limits in Size of Taylor Dispersion Analysis: Representation of the Different Hydrodynamic Regimes and Application to the Size-Characterization of Cubosomes. Anal. Chem. 2017, 89, 13487-13493.

(27) Urban, D. A.; Milosevic, A. M.; Bossert, D.; Crippa, F.; Moore, T. L.; Geers, C.; Balog, S.; Rothen-Rutishauser, B.; Petri-Fink, A. Taylor Dispersion of Inorganic Nanoparticles and Comparison to Dynamic Light Scattering and Transmission Electron Microscopy. Colloid Interf Sci. Communications, 2018, 22, 29-33.

(28) Chamieh, J.; Cottet H. Comparison of single and double detection points Taylor Dispersion Analysis for monodisperse and polydisperse samples. J. Chromatogr. A 2012, 1241, 123- 127.

(29) Cipelletti, L.; Biron, J.-P.; Martin, M.; Cottet, H. Measuring Arbitrary Diffusion Coefficient Distributions of Nano-Objects by Taylor Dispersion Analysis. Anal. Chem. 2015, 87, 8489-8496.

(30) Yang, X.; Bolsa-Ferruz, M.; Marichal, L.; Porcel, E.; SaladoLeza, D.; Lux, F.; Tillement, O.; Renault, J.-P.; Pin, S.; Wien, F.; Lacombe, S. Human Serum Albumin in the Presence of AGuIX Nanoagents: Structure Stabilisation without Direct Interaction. Int. J. Mol. Sci. 2020, 21, 4673. 
For Table of Contents Only

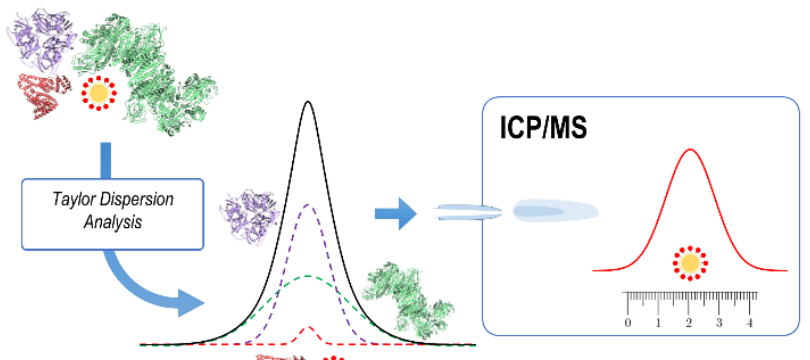

\%? 